\title{
Teucrium polium Extract Enhances the Anti-Angiogenic Effect of Tranilast in a Three-Dimensional Fibrin Matrix Model
}

\author{
Fatemeh Sheikhbahaei ${ }^{1}$, Seyed Noureddin Nematollahi-Mahani ${ }^{2 *}$, Mozafar \\ Khazaei $^{3}$, Mohammad Rasool Khazaei ${ }^{3}$, Saeed Khazayel ${ }^{3}$
}

\begin{abstract}
Objective: Angiogenesis plays a dominant role in many pathophysiologic disorders, including cancer. Tranilast, which is an anti-fibrotic drug, is also suggested as an anti-angiogenesis agent. As Teucrium polium (TP) is known as an herbal medicine with antitumor properties, this study aimed to investigate the effects of TP and Tranilast on human umbilical vein endothelial cells (HUVECs), in vitro model of angiogenesis, as well as rat's aortic ring ex vivo model. Methods: In this study, The HUVECs were treated with various doses of TP and Tranilast each one alone or in combination together. Cell survival test, aortic ring ex-vivo assay, and evaluating mRNA expressions of VEGFA and TGF- $\beta$ ligands and receptors were performed. Results: The survival rate of HUVECs has significantly $(p<0.05)$ reduced by TP and Tranilast. The combination of both TP and Tranilast significantly reduced cell viability as compared to the administration of TP or Tranilast alone. As well, the treatment of HUVECs with TP and/or Tranilast significantly $(\mathrm{p}<0.05)$ decreased TGF- $\beta 1$, TGF- $\beta 2$, TGF- $\beta$ RI, and TGF- $\beta$ RII mRNA expression levels, but not the expression of TGF- $\beta 3$ and TGF- $\beta$ RIII in the TP-treated cells. Image analysis showed that TP and/or Tranilast inhibited vascular growth in the aortic ring assay. Conclusion: Our results strongly support the anti-angiogenic effects of the TP and Tranilast combination on both in vitro and ex vivo models of angiogenesis. However, further investigations in in vivo models and human studies are needed before human use.
\end{abstract}

Keywords: Angiogenesis inhibitors- Teucrium polium- tranilast- HUVEC- aortic rings

Asian Pac J Cancer Prev, 22 (8), 2471-2478

\section{Introduction}

Angiogenesis inhibition, as a promising approach for cancer therapies, is rather essential for both tumor's development and maintenance (Scappaticci, 2002). It is crucial to investigate numerous biological functions such as physiologic regeneration in ovulation; embryonic development; and pathologic changes such as diabetic retinopathy, rheumatoid arthritis, and solid cancers growth (Hanahan and Folkman, 1996). Angiogenesis is a well-organized series of events, which are usually started by the destruction in tissues and hypoxia. Following angiogenic factors' activation, it was shown that endothelial cells migrate, proliferate, stabilize, and finally expedite the angiogenic processes (Nishida et al., 2006).

Angiogenesis mostly depends on the balance between the activation of inhibitory and stimulatory molecules that could stop or initiate this incident (Sheikhbahaei et al., 2018). Accordingly, this is regulated by various growth factors, chemokines, and cytokines. Moreover, different proteins have been introduced as angiogenic activators, including vascular endothelial growth factor A(VEGFA), basic fibroblast growth factor (bFGF), transforming growth factor (TGF)- $\alpha$, TGF- $\beta$, hepatocyte growth factor, and epidermal growth factor. Among these, VEGFA and TGF- $\beta 1$ were observed to play a prominent role in the regulation of angiogenesis (Ferrari et al., 2009). In this regard, VEGFA has been proved as a pivotal regulator of angiogenic process. Proliferation, survival, and migration are directed by this factor in endothelial cells (Otrock et al., 2007). In addition, VEGFA also plays a principle role in malignant tumors growth through neovascularization, and it can be up regulated by oncogenes expression (Carmeliet, 2005). Hence, the inhibition of VEGFA has been considered for the suppression of angiogenesis as well as the treatment of solid tumor malignancies (Ferrari et al., 2006). It was shown that Transforming growth factor- $\beta$ (TGF- $\beta$ ) could regulate several biological processes such as proliferation, apoptosis, migration, tumorigenesis, and angiogenesis. Additionally, there are three isoforms of

${ }^{1}$ Department of Anatomy, Afzalipour School of Medicine, Kerman University of Medical Sciences, Kerman, Iran. ${ }^{2}$ Physiology Research Center, Institute of Neuropharmacology, Kerman University of Medical Sciences, Kerman, Iran. ${ }^{3}$ Fertility and Infertility Research Center, Health Technology Institute, Kermanshah University of Medical Sciences, Kermanshah, Iran. *For Correspondence: nnematollahi@kmu.ac.ir 
TGF- $\beta$ (including $\beta 1, \beta 2$, and $\beta 3$ ) and three TGF- $\beta \mathrm{s}$ receptors, including I, II, and III (Darakhshan and Pour, 2015). It was reported that TGF- $\beta$ s, which are produced by tumor cells, could stimulate tumorigenesis through inducing angiogenesis (Massagué, 2008). Several previous studies have proved the importance of TGF- $\beta$ signaling pathway in angiogenesis (Goumans et al., 2003). It is obvious that both VEGFA and TGF- $\beta$ s inhibition can be proposed as a decisive novel therapy for solid tumors.

Tranilast (N- [3, 4-dimethoxycinnamonyl]-anthranilic acid) was firstly introduced in 1976 as a drug used for the treatment of allergic disorders, hypertrophic scars, and keloids. Tranilast inhibits fibroblasts proliferation and subsequently suppresses collagen deposition. Aside from these, Tranilast was found to inhibit the release of TGF- $\beta$ from fibroblasts (Sheikhbahaei et al., 2018). Antitumor effects of this agent have also been reported in some cell lines (Platten et al., 2001; Izumi et al., 2009). Moreover, it could block cell cycle progression of both MDA-MB- 231 and BT-474 cells (Nie et al., 1997). The Antiangiogenic effects of Tranilast on human dermal microvascular endothelial cells was found to be through the inhibition of the proliferation, tube formation, and expression of VEGFA (Isaji et al., 1997).

Combination therapies with herbal extracts have recently received great interest as suitable solutions to overcome drug resistance and also to increase the drug potency (Nathan and Scholten, 1999). Teucrium polium (TP) belongs to the Lamaceae family, which has long been used in traditional medicine due to its pharmacological properties. Accordingly, it has antipyretic, antioxidant, antibacterial, anti-inflammatory, hypolipidemic and antiseptic properties. Moreover, the anticancer properties of TP on a variety of cancer cell lines have been studied (Khazaei et al., 2018). The antitumor potentials of the different fractions of TP have been investigated as well, indicating that petroleum ether fraction is the most potent fraction on U87 cells (Nematollahi-Mahani et al., 2012). As the inhibition of angiogenesis is currently considered for both the tumor growth inhibition and metastasis, our previous study also indicated that the combination of TP and Tranilast could inhibit angiogenesis in HUVECs, leading to the reduced cell viability, the increased apoptosis, and the decreased migration capacity of these cells. Therefore, this research aimed to investigate wheather the Tranilast and TP combination could affect endothelial cells spurting in a three-dimensional aortic ring assay in an in vivo model of angiogenesis, and to understand the probable molecular changes in the angiogenesis pathway.

\section{Materials and Methods}

The ethics committee of Kermanshah University of Medical Sciences approved this study. In addition, the studied animals received care as recommended by the Ethics Research Committee of the Kermanshah University of Medical Sciences (EC/KNRC/90-4) in terms of the internationally accepted principles for laboratory animal use and care, as proposed in the European Community guidelines (EEC Directive of 1986; 86/609/EEC).

\section{Material}

Extraction of the Plant Material

The areal parts of TP were collected from Kerman, Iran, and then identified at the Department of Pharmacognosy, faculty of Pharmacy, Kerman University of Medical Sciences. Thereafter, a specimen was deposited at the herbarium of the Kerman Faculty of Pharmacy (Voucher number: 28125). Finally, Methanolic extraction followed by petroleum ether fractionation were conducted as described earlier (Sheikhbahaei et al., 2018).

\section{Cell line and reagents}

For this in vitro experimental study, HUVECs were purchased from the National Cell Bank (Tehran, Iran). Moreover, the culture media and reagents were obtained from Sigma-Aldrich Chemical Co (St. Louis, MO, USA), unless otherwise stated.

\section{Cell culture and treatment}

The cells were cultured in T75 flasks containing DMEM/F12 medium supplemented with 10\% FBS (complete medium) at $37^{\circ} \mathrm{C}$ in a humidified atmosphere of $5 \% \mathrm{CO} 2$. In our previous study, for dose response, the cells were treated for 24, 48, and $72 \mathrm{~h}$ with 25, 50, 100, 200 , and $400 \mu \mathrm{g} / \mathrm{ml}$ petroleum ether (PE) fraction of TP, along with $75,150,300,600$, and $1200 \mu \mathrm{M}$ of Tranilast dissolved in DMSO. Subsequently, for the analysis of median effect, the fixed ratio drug combinations were done according to $\mathrm{IC}_{50}$ values of TP and Tranilast using GraphPad Prism 5 (GraphPad Software Inc., La Jolla, CA, USA). For performing other tests, concentrations of $100 \mu \mathrm{g} / \mathrm{ml}$ of TP and/or $300 \mu \mathrm{M}$ of TQ (about their $\mathrm{IC}_{50} \mathrm{~s}$ ) were chosen. Notably, each treatment was replicated at least three times.

\section{Animals}

Male Wistar rats weighing $200 \pm 250$ g were obtained from animal house of Kermanshah University of Medical Sciences, Kermanshah, Iran. Next, they were maintained under 12:12 hour light/dark cycle and fed with standard pellet chow and watered libitum.

\section{Methods \\ Viability assay using trypan blue exclusion test}

At this stage, HUVECs were seeded in 24-well plates at a density of $7 \times 10^{4}$ per well for $24 \mathrm{~h}$. The culture medium was replaced with a fresh DMEM/F12 medium containing various concentrations of both Tranilast and TP. The plates were incubated for 24,48 , and $72 \mathrm{~h}$ at $37^{\circ}$ $\mathrm{C}$ in a humidified atmosphere with $5 \% \mathrm{CO}_{2}$. These cells were then trypsinized and the cell suspension was also mixed with an equal volume of $0.4 \%$ trypan blue solution. Thereafter, this mixture was transferred to an improved Neubauer hemacytometer and then analyzed under a light microscope at $\times 40$. Finally, the number of the alive cells (unstained) versus the total number of the cells was calculated as the percentage of viability (Strober, 2001).

\section{Real time RT-PCR}

The effects of various concentrations of Tranilast and $\mathrm{TP}$ on the expression levels of some angiogenic-related 
genes were analyzed using real-time PCR. Total RNA was prepared from HUVECs using the GeneMATRIX Universal RNA Purification Kit (EurX, Poland), in terms of the manufacturer's instructions. Afterward, Complementary DNA (cDNA) was synthesized using cDNA synthesis kit (reverse transcription PrimeScriptTM RT Reagent Kit, Takara. Japan) in $20 \mu \mathrm{l}$ of the reaction mixture in terms of the manufacturer's instructions. Realtime PCR was then performed using SYBR Premix Ex Taq technology (Takara Bio Inc. Japan) on the Applied Biosystems Real-Time PCR One Step System in triplicate. In this process, ACTB was used as an internal control. As well, the primers were designed using the Bio Edit and BLAST programs. (http://www.ncbi.nlm.nih.gov) After analyzing the obtained data using One Step Software v3.2, the relative expression level of these genes was calculated using two $-\Delta \Delta C T$ formula. Subsequently, the primers were designed using the Bio Edit program, and also a BLAST search (http://www.ncbi.nlm.nih.gov) was performed to confirm the specificity of the selected nucleotide sequences. Correspondingly, the primers are listed in Table 1.

\section{Rat aortic ring assay}

The study rats were anaesthetized with intraperitoneal (i.p.) injection of chloral hydrate $(350 \mathrm{mg} / \mathrm{kg})$. Thoracic aortae were removed from male rats aged between 8 and 12 weeks old, and were then cut into 1-2 mm rings, carefully. Fibrin scaffold was used for three-dimensional (3D) culturing. Using this method, fibrinogen $(3 \mathrm{mg} / \mathrm{mL})$ was dissolved in a M199 medium and then added to each well of a 24 -well plate $(0.5 \mathrm{~mL} /$ well $)$. Afterward, $15 \mu \mathrm{L}$ of thrombin (Stago) was added to each one of these wells. After the gel formation, aorta rings were embedded in the center of the wells and then covered by an additional $0.5 \mathrm{~mL}$ of fibrinogen/thrombin solution. When the first vascular sprouts from the aortic rings appeared, they were treated with $300 \mu \mathrm{M}$ of Tranilast or $100 \mu \mathrm{g} / \mathrm{ml}$ of
$\mathrm{TP}$ as well as their combination. Next, the explants were cultured for 10 days at $37^{\circ} \mathrm{C}$ in a humidified atmosphere of $5 \% \mathrm{CO} 2$. Aorta rings were daily observed, and were photographed on both days 0 and 10 using an inverted microscope (AE-31; Motic, Barcelona, Spain). Moreover, angiogenesis was assessed according to the number of the wells using a scale from 0 (no growth) to 1-4 (tissue growth and changes [cell invasion into fibrin matrix] seen in $<25 \%, 26 \%-50 \%, 51 \%-75 \%$, and $>75 \%$ of the cultured tissues, respectively), showing different stages of growth (Aplin et al., 2008).

\section{Statistical analysis}

The statistical analyses of this study were conducted by SPSS software, version 16 (SPSS Inc., Chicago, IL, $\mathrm{USA}$ ) with mean $\pm \mathrm{SD}$. One-way analysis of variance ANOVA test was used to determine the significance of differences amongst the different studied groups. All the obtained data were reported as mean \pm standard error of mean (SEM). A p-value less than 0.05 was considered as statistically significant.

\section{Results}

Viability assay

Viability decreased from the starting dose of $25 \mu \mathrm{g} /$ $\mathrm{ml}$ of TP and dose-dependently continued at either of the time intervals tested. Of note, the highest decrease of the viability was observed at $400 \mu \mathrm{g} / \mathrm{ml}$ and the $\mathrm{IC}_{50}$ was calculated to be $107 \mu \mathrm{g} / \mathrm{ml}$ (Figure 1.a). The treatment of the HUVEC cells with the starting dose of tranilast (75 $\mu \mathrm{M})$ showed no significant effect on the viability rate after 24 and $48 \mathrm{~h}$, but it decreased after $72 \mathrm{~h}$ incubation. Thereafter, by $\mathrm{IC}_{50}$ the Tranilast dose to $1200 \mu \mathrm{M}$, a lower viability rate was observed in HUVECs and the $\mathrm{IC}_{50}$ was calculated as $302 \mu \mathrm{g} / \mathrm{ml}$ (Figure 1.b). As well, the combined treatment with TP and Tranilast resulted in a lower viability rate compared to each one of the single

Table 1. Primer Sequences Utilized for Real-Time PCR

\begin{tabular}{|c|c|c|c|c|}
\hline Gene & Accession Number & Annealing temperature, ${ }^{\circ} \mathrm{C}$ & Size (bp) & Primer sequence \\
\hline \multirow[t]{2}{*}{$\overline{A C T B}$} & NM_001101 & 60 & 146 & F: 5'-TGACCCAGATCATGTTTGAGACC-3' \\
\hline & & & & R: 5'-CTCGTAGATGGGCACAGTGTGGG-3' \\
\hline \multirow[t]{2}{*}{$V E G F A$} & NM_001025366 & 60 & 105 & F: 5'-ATTATGCGGATCAAACCT-3' \\
\hline & & & & R: 5'-TTCTTGTCTTGCTCTATCTT-3' \\
\hline \multirow[t]{2}{*}{ TGFB1 } & NM_000660 & 60 & 218 & F: 5'-AAGTGGACATCAACGGGTTC-3' \\
\hline & NM_000661 & & & R: 5'-GTCCTTGCGGAAGTCAATGT-3' \\
\hline \multirow[t]{2}{*}{$T G F B 2$} & NM_001135599 & 60 & 154 & F: 5'-CCATCCCGCCCACTTTCTAC-3' \\
\hline & & & & R: 5'-AGCTCAATCCGTTGTTCAGGC-3' \\
\hline \multirow[t]{2}{*}{$T G F B 3$} & NM_003239 & 60 & 201 & F: 5'-CAAAGGCGTGGACAATGAG-3' \\
\hline & & & & R: 5'-ACACAGCAGTTCTCCTCC-3' \\
\hline \multirow[t]{2}{*}{ TGFBR1 } & NM_001306210 & 60 & 138 & F: 5'-ACATGATTCAGCCACAGATACC-3' \\
\hline & & & & R: 5'-GCATAGATGTCAGCACGTTTG-3' \\
\hline \multirow[t]{2}{*}{$T G F B R 2$} & NM_001024847 & 60 & 132 & F: 5'-GTAGCTCTGATGAGTGCAATGAC-3' \\
\hline & & & & R: 5'-CAGATATGGCAACTCCCAGTG-3' \\
\hline \multirow[t]{2}{*}{$T G F B R 3$} & NM_003243 & 60 & 170 & F: 5'-CCTTCCGTTTCCTTTCCCAGA-3' \\
\hline & & & & R: 5'-CACATTTGACAGACAGGGCAAT-3' \\
\hline
\end{tabular}




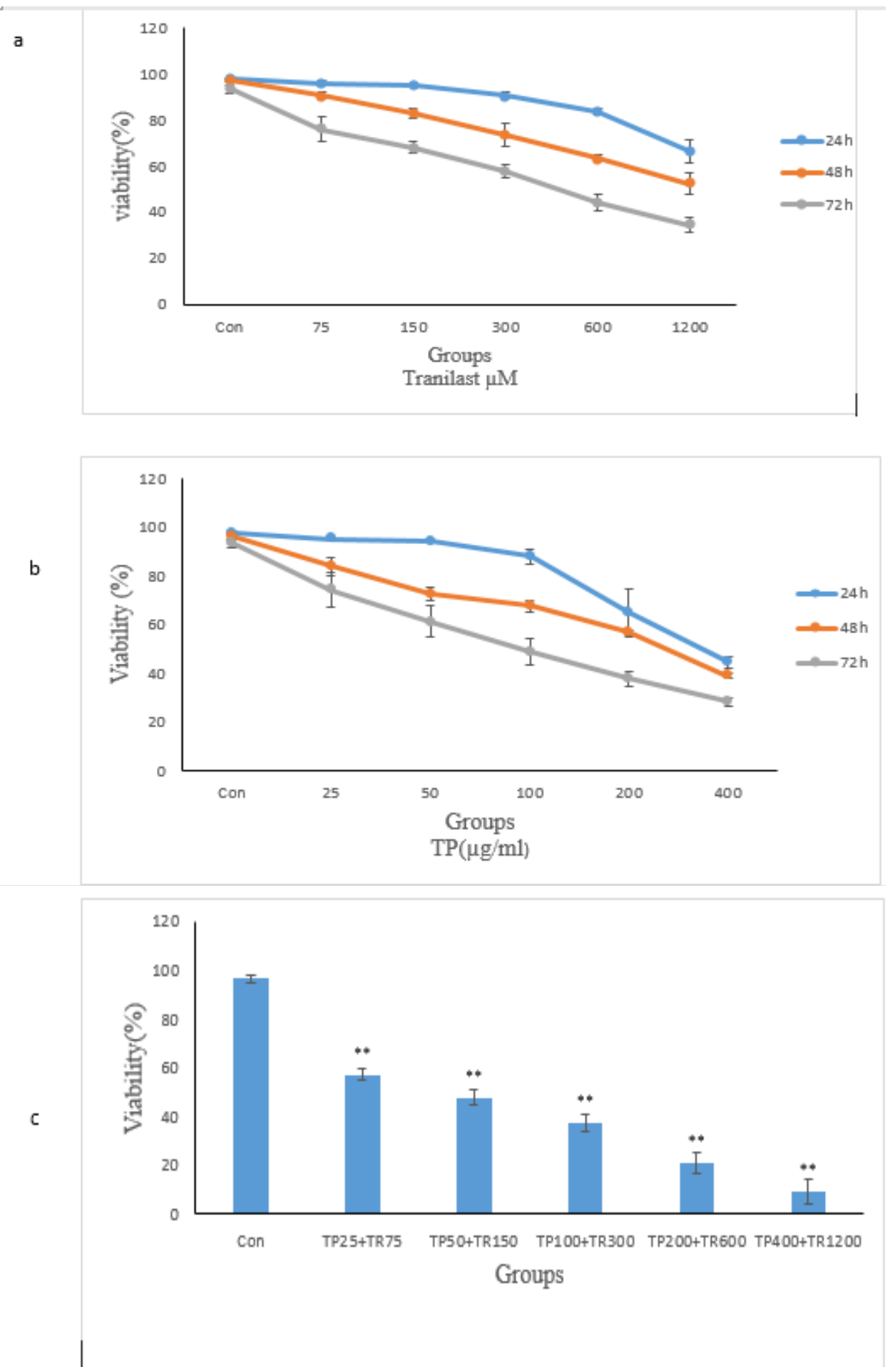

Figure 1. the Effects of the Administrations of TP and Tranilast Alone and in Combination on HUVECs Viability Assessed by Trypan Blue Staining. The cells were treated with $T P$ and/or Tranilast for 24,48 , and $72 \mathrm{~h}$ and viability was measured by Trypan blue staining. The control wells were treated with equivalent amount of medium alone. The values are defined as the mean and SE from the triplicated experiments.

treatment protocols (Figure 1.c) (Sheikhbahaei et al., 2018).

The effects of TP, Tranilast, and their combination on $m R N A$ levels of VEGFA and TGF- $\beta$ ligands and receptors in HUVECS

The exposure of HUVECs to both TP and Tranilast alone or in combination for $72 \mathrm{~h}$ decreased the expression levels of TGF- $\beta 1$, TGF- $\beta 2$, TGF- $\beta 3$, TGF $\beta$-RI, and TGF- $\beta$ RII mRNA. The expression levels of both TGF- $\beta 1$ and TGF- $\beta 2$ significantly reduced in the Tranilast (fold changes: 0.50 and 0.57 ) and TP (fold changes: 0.63 and $0.69)$ treated cells compared to the control. The combined treatment reduced the mRNA expression levels of TGF- $\beta 1$ (fold change: 0.46 ) and TGF- $\beta 2$ (fold change: 0.47 ), but they were higher than each one of the single treatments. TGF $\beta 3$ gene expression level was comparable in the TP treatment (fold change: 0.73 ), but it was significantly 

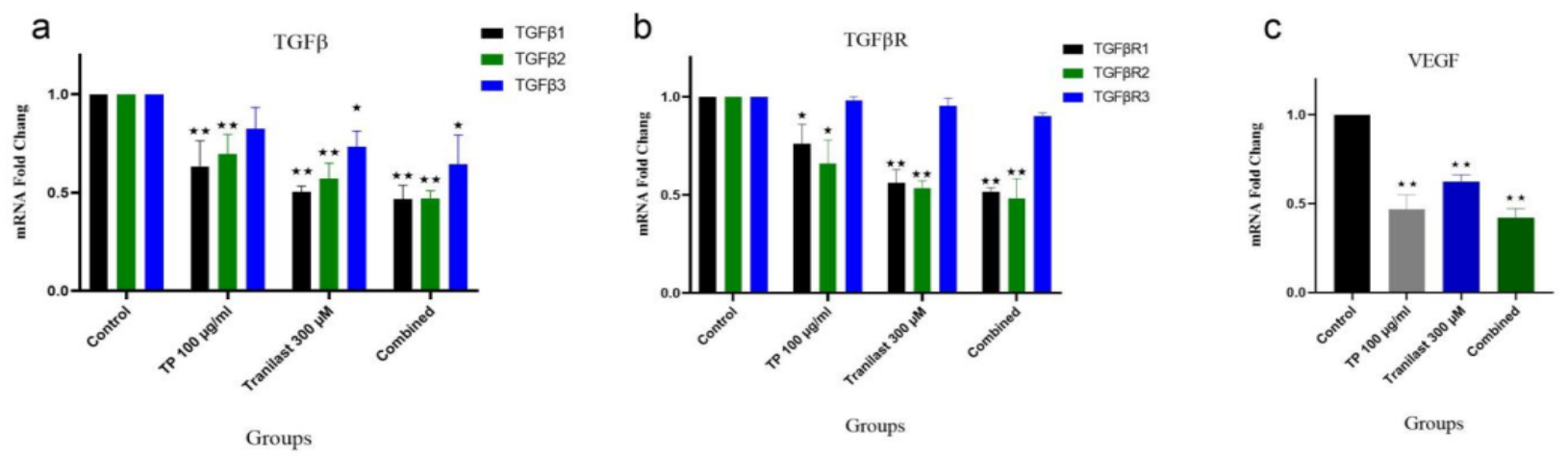

Figure 2. Quantitative RT-PCR Analysis for: a) TGF $\beta$, b) TGF $\beta$, and c) VEGFA genes in HUVECs. Data are expressed as mean \pm SEM of three dependent experiments. A significantly difference was observed compared with the control $* \mathrm{p}<0.05, * * \mathrm{p}<0.001$.

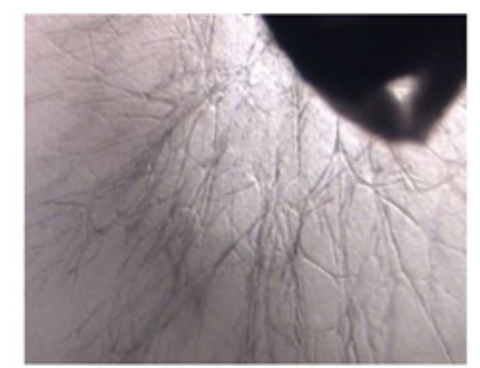

A

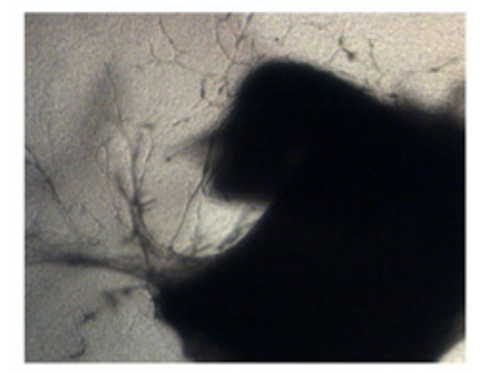

$\mathrm{C}$

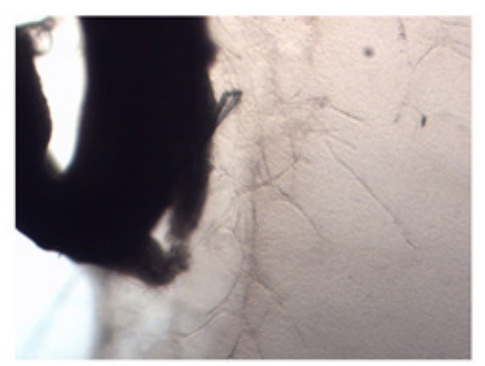

B

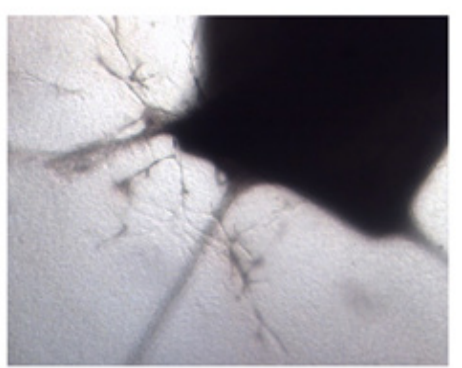

D

Figure 3. Inverted Micrographs Showing Vessel Outgrowth Raised from the Rat Aorta Rings into Fibrin Matrix on the Day 10 of Culturing (a) the control, (b) $300 \mu \mathrm{M}$ Tranilast, (c) $100 \mu \mathrm{g} / \mathrm{ml} \mathrm{TP}$, and (d) combined groups.

lower in Tranilast compared with the control (fold change: 0.64). Correspondingly, it also significantly decreased in the combined treatment group. The expressions of TGF $\beta$-RI and TGF $\beta$-RII genes significantly altered by both TP (TGF $\beta$-RI fold change: 0.76 and TGF $\beta$-RII fold change: 0.66 ) and Tranilast (TGF $\beta$-RI fold change: 0.56 and TGF $\beta$-RII fold change: 0.54 ) alone and also in the combination. Moreover, TGF $\beta$ R3 expression level did

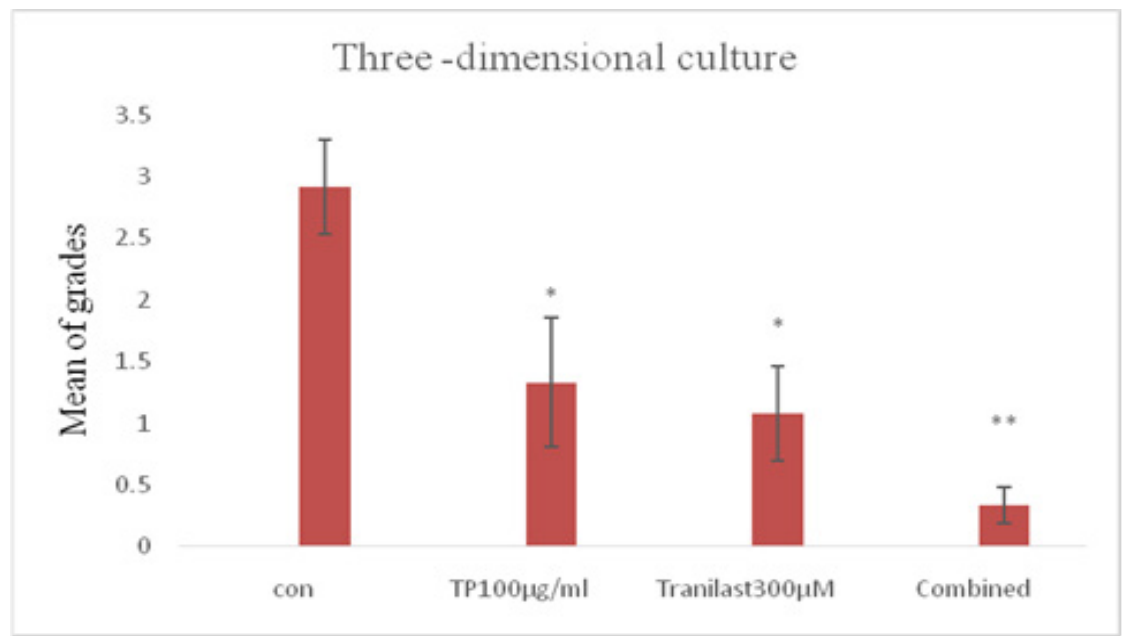

Figure 4. The Mean Score Obtained in the Control, 300 $\mu \mathrm{M}$ Tranilast, $100 \mu \mathrm{g} / \mathrm{ml} \mathrm{TP}$, and Combined Groups; $(* \mathrm{P}<0.05 ; * * \mathrm{P}<0.001$ compared with the control). 
not significantly decreased in the TP treatment group, but it significantly reduced in the Tranilast group (fold change: 0.79 ) and the combined treatment (fold change: 0.75) as compared to its levels in control cells (Figure 3). Additionally, Tranilast and TP reduced the expressions of the VEGFA gene (fold change: 0.47 and 0.62 , respectively) in HUVECs. As well, the combination treatment highly decreased VEGFA expression (fold change: 0.42) (Figure 2).

The effects of TP, Tranilast, and their combination on rat's microvessel outgrowth

Microscopic findings revealed vessel outgrowth raised from the rings into fibrin matrix on the day 10 of culturing. To determine whether the treatments could affect neovessel outgrowth, aorta rings were treated with $300 \mu \mathrm{M}$ Tranilast, $100 \mu \mathrm{g} / \mathrm{ml} \mathrm{TP}$ or their combination. According to the scoring system, the mean $\pm \mathrm{SD}$ of the calculated angiogenesis response was estimated as $2.91 \pm$ 0.38 in the control group, $1.08 \pm 0.38$ in the $300 \mu \mathrm{M}$ Tranilast, $1.33 \pm 0.52$ in the $100 \mu \mathrm{g} / \mathrm{ml} \mathrm{TP}$, and $0.33 \pm$ 0.14 in the combined group. It was observed that the combination of TP and Tranilast significantly inhibited angiogenesis $(p<0.001)$ more than the administration of TP or Tranilast alone $(\mathrm{p}<0.05)$ (Figures 3 and 4$)$.

\section{Discussion}

Recently, we have reported that the combined treatment of HUVECs with TP and Tranilast could exert a synergistic effect on the proliferation capacity of HUVEC cells examined by MTT assay. In this regard, the combination index value estimated between 0.71 and 0.21 confirmed the synergistic effects of TP and Tranilast (Sheikhbahaei et al., 2018) .In the present study, trypan blue staining test also demonstrated that the HUVECs responded to the cytotoxic effects of the administered drugs both dose- and time-dependently. The combined treatment of the cells with these two drugs consequently reduced cell viability much higher than that of the TP and Tranilast alone. The most anti-proliferative properties of TP can be attributed to flavonoids and terpenoids. Components in TP influence variety of cell functions, which eventually result in the inhibition of cell proliferation (STANKOVIĆ et al., 2015). On the other hand, Tranilast decreases growth and differentiation of some cancerous cells, including prostate cancer cells (CU 145, PC3, (LNcap) (Murahashi et al., 1998) by increasing phosphorylation of AKT1 and decreasing the phosphorylation of ERK1 / 2 as well as G1/S cell cycle arrest in murine breast cancer cell line (Subramaniam et al., 2010). Our results are consistent with those of a previous study in which combined treatment with $\mathrm{TP} /$ vinblastine has decreased the survival rate of human cancer cell lines such as A431 MCF7, Skmel3, SW480, and EJ(Rajabalian, 2008). Angiogenesis is regulated through growth factors, cytokines, and chemokines; the most important of which are VEGFA, TGF- $\alpha$, TGF- $\beta$, and bFGF (Ferrari et al., 2009). Accordingly, VEGFA induces endothelial cells proliferation, sprouting, and tubal formation under both in vivo and in vitro conditions (Otrock et al., 2007). It has been proved that TGF- $\beta$ induces angiogenesis by regulating VEGFA expression for the spread and tumor metastasis, which is, in part, inhibited by Tranilast (Isaji et al., 1997). In the current study, we showed that Tranilast, TP, and their combination have the ability of decreasing VEGFA gene expression level in HUVECs, which results in the inhibition of angiogenesis. (Isaji et al., 1997). Koyama et al. in their study showed that Tranilast significantly inhibited VEGFA and bFGF in a dose-dependent manner (Koyama et al., 1999). In mammals, TGF $\beta$ has three isoforms (namely TGF $\beta 1$, $\beta 2$, and $\beta 3$ ) as well as three receptor isoforms (namely TGF $\beta$-RI, TGF $\beta$-RII, and TGF $\beta$-RIII). Some researchers have revealed that TGF $\beta$ pathway plays a complex role in carcinogenesis, so that it performs both stimulatory and inhibitory effects on tumor vessel growth (Pardali et al., 2010). For instance, it was demonstrated that the TGF- $\beta$ signaling pathway acts as a tumor suppressor at early stage of mammary carcinogenesis(Elliott and Blobe, 2005), while at later stages, as tumor progresses, levels of TGF- $\beta$ increase and then it acts as a breast cancer stimulator (Walker and Dearing, 1992). In this regard, both TGF- $\beta 1$ and TGF- $\beta$ RII as important signaling pathways in angiogenesis, have been reported as the fundamental molecules for both vasculogenesis and Angiogenesis (Goumans et al., 2003). The use of a neutralizing antibody against TGF- $\beta$ has also been proposed to inhibit angiogenesis (Duff et al., 2003).

The present study showed that the exposure of HUVECs to TP and Tranilast alone or in combination decreases the expression levels of TGF- $\beta 1$, TGF- $\beta 2$, TGF- $\beta 3$, TGF $\beta$-RI, and TGF $\beta$-RII mRNA. However, it did not significantly decrease TGF $\beta 3$ and TGF $\beta$-RIII following the TP treatment. Our findings are consistent with the results of a study by Izumi et al. (2009), who showed a dose-dependent inhibitory effect of Tranilast on TGF $\beta$ secretion in PC3 and Saos-2 cell lines (Izumi et al., 2009).

In another study, Yamamoto et al., (2009) investigated the effect of Tranilast on the growth of neurofibroma cells. Correspondingly, Tranilast inhibited the TGF $\beta$ secretion from fibroblasts, which plays an essential role in the treatment of keloids and hypertrophic scars (Yamamoto et al., 2009). Although the combination of Tranilast and tamoxifen has also decreased the expression levels of TGF $\beta 1$, TGF- $\beta 2$, TGF- $\beta 3$ TGF $\beta$-RI, and TGF $\beta$-RII, it increased the level of TGF $\beta$-RIII in breast cancer cells (MCF-7) (Darakhshan and Ghanbari, 2013).

Ex-vivo aortic ring model could put the advantages of both in vivo and in vitro assays together and then bridges the gap between these two models. Of note, it was demonstrated that Neovessels growth occurs in a determined environment, and the culture system can be easily adapted to different experimental conditions (Nicosia and Villaschi, 1995).

In vitro angiogenesis assays include proliferation, migration, and the formation of tube-like structures by endothelial cells (Park et al., 2016). According to our recent study on TP and/or Tranilast, as a result, these induced anti-angiogenic effects on HUVECs through cell viability alteration, a decrease in migration capacity, and an increase in the apoptosis of these cells (Sheikhbahaei et al., 
2018). In the present study, we evaluated the angiogenic response of rat aortic rings to the administrations of $\mathrm{TP}$ and Tranilast alone and in combination. As well, the aortic outgrowth was evaluated by scoring new micro-vessels every 3 days for a 10-day duration. Subsequently, the treatment of rat aortic rings by TP and Tranilast led to a sharp decrease in vessels' formation and extension. Moreover, TP has shown some antiproliferative effects on some cancer cell lines (Khazaei et al., 2018), which is a property that could be related to the anti-angiogenic effects of TP on HUVECs, as well. (Dehghan et al., 2016). The treatment of rat aortic rings with different doses of Eugenol has also resulted in the decreased new vessel formation and vascular sprouts extension after $48 \mathrm{~h}$ (Kouhestanian et al., 2015). However, other angiogenesis models such as chick chorioalantoic membrane and tumor inoculation, in an animal model like mice could strengthen our outcomes before coming to a reliable conclusion on the application of the TP and Tranilast combined treatment in human beings.

In conclusion, the results of the present study clearly demonstrated that the combination of TP and Tranilast can provide a more significant anti-angiogenic effect compared with a single application in in vitro angiogenesis (HUVECs) as well as in ex vivo model of angiogenesis. However, further animal studies and clinical trials are required to evaluate the inhibitory therapeutic potential of the TP and Tranilast combination in the treatment strategies related to hyper-angiogenic diseases.

\section{Author Contribution Statement}

F. Sheikhbahaei, SN. Nematollahi-Mahani and M. Khazaei were involved in experimental designs and carrying out the experiments. F. Sheikhbahaei and SN. Nematollahi-Mahani drafted the original manuscript. MR. Khazaei and S. Khazayel collected and analyzed the data. All authors approved the final version of the manuscript.

\section{Acknowledgements}

This study was a part of Ph.D. thesis. The study was approved by ethics board committee of Kerman University of Medical Science, Kerman, Iran. Ethical code: IR KMU. REC.1395.152. The authors appreciate the financial support of this research by Kerman and Kermanshah Universities of Medical Sciences.

\section{Conflict of Interest Statement}

All authors declare no conflict of interest for this study.

\section{References}

Aplin AC, Fogel E, Zorzi P, et al (2008). The aortic ring model of angiogenesis. Meth Enzymol, 443, 119-36.

Carmeliet P (2005). VEGF as a key mediator of angiogenesis in cancer. Oncology, 69, 4-10.

Darakhshan S, Ghanbari A (2013). Tranilast enhances the antitumor effects of tamoxifen on human breast cancer cells in vitro. J Biomed Sci, 20, 76.

Darakhshan S, Pour AB (2015). Tranilast: a review of its therapeutic applications. Pharmacol Res, 91, 15-28.
Dehghan MH, Mirmiranpour H, Faghihi-Kashani S, et al (2016). Inhibitory effect of curcumin on angiogenesis in a streptozotocin-induced diabetic rat model: An aortic ring assay. J Tradit Complement Med, 6, 437-41.

Duff SE, Li C, Garland JM, et al (2003). CD105 is important for angiogenesis: evidence and potential applications. FASEB J, 17, 984-92.

Elliott RL, Blobe GC (2005). Role of transforming growth factor Beta in human cancer. J Clin Oncol, 23, 2078-93.

Ferrari G, Cook BD, Terushkin V, et al (2009). Transforming growth factor-beta 1 (TGF- $\beta 1$ ) induces angiogenesis through vascular endothelial growth factor (VEGF)- mediated apoptosis. J Cell Physiol, 219, 449-58.

Ferrari G, Pintucci G, Seghezzi G, et al (2006). VEGF, a prosurvival factor, acts in concert with TGF- $\beta 1$ to induce endothelial cell apoptosis. Proc Natl Acad Sci U S A, 103, 17260-5.

Goumans M-J, Lebrin F, Valdimarsdottir G (2003). Controlling the angiogenic switch: a balance between two distinct TGF-b receptor signaling pathways. Trends Cardiovasc Med, 13, 301-7.

Hanahan D, Folkman J (1996). Patterns and emerging mechanisms of the angiogenic switch during tumorigenesis. Cell, 86, 353-64.

Isaji M, Miyata H, Ajisawa Y, et al (1997). Tranilast inhibits the proliferation, chemotaxis and tube formation of human microvascular endothelial cells in vitro and angiogenesis in vivo. Br J Pharmacol, 122, 1061-6.

Izumi K, Mizokami A, Li YQ, et al (2009). Tranilast inhibits hormone refractory prostate cancer cell proliferation and suppresses transforming growth factor $\beta 1$-associated osteoblastic changes. Prostate, 69, 1222-34.

Khazaei M, Nematollahi-Mahani SN, Mokhtari T, et al (2018). Review on Teucrium polium biological activities and medical characteristics against different pathologic situations. J Contemp Med Sci, 4.

Kouhestanian K, Baharara J, Zafarbalanezhad S (2015). Anti-angiogenic effect of eugenol on a Wistar rat aortic ring. Feyz J Kashan Univ Med Sci, 19.

Koyama S, Takagi H, Otani A, et al (1999). Tranilast inhibits protein kinase $\mathrm{C}$-dependent signalling pathway linked to angiogenic activities and gene expression of retinal microcapillary endothelial cells. Br J Pharmacol, 127, $537-45$.

Massagué J (2008). TGFß in cancer. Cell, 134, 215-30.

Murahashi K, Yashiro M, Inoue T, et al (1998). Tranilast and cisplatin as an experimental combination therapy for scirrhous gastric cancer. Int J Oncol, 13, 1235-75.

Nathan M, Scholten R (1999). The complete German Commission E monographs: therapeutic guide to herbal medicines. Ann Intern Med, 130, 459-.

Nematollahi-Mahani SN, Mahdinia Z, Eftekharvaghefi R, et al (2012). In vitro inhibition of the growth of glioblastoma by teucrium polium crude extract and fractions. Int Phytomedicine, 4, 582.

Nicosia RF, Villaschi S (1995). Rat aortic smooth muscle cells become pericytes during angiogenesis in vitro. Lab Invest J Technic Meth Pathol, 73, 658-66.

Nie L, Oishi Y, Doi I, et al (1997). Inhibition of proliferation of MCF-7 breast cancer cells by a blocker of $\mathrm{Ca} 2+-$ permeable channel. Cell Calcium, 22, 75-82.

Nishida N, Yano H, Nishida T, et al (2006). Angiogenesis in cancer. Vasc Health Risk Manag, 2, 213.

Otrock ZK, Mahfouz RA, Makarem JA, et al (2007). Understanding the biology of angiogenesis: review of the most important molecular mechanisms. Blood Cells $\mathrm{Mol}$ Dis, 39, 212-20. 
Pardali E, Goumans M-J, ten Dijke P (2010). Signaling by members of the TGF- $\beta$ family in vascular morphogenesis and disease. Trends Cell Biol, 20, 556-67.

Park E-H, Park JY, Yoo H-S, et al (2016). Assessment of the anti-metastatic properties of sanguiin H-6 in HUVECs and MDA-MB-231 human breast cancer cells. Bioorg Med Chem Lett, 26, 3291-4.

Platten M, Wild-Bode C, Wick W, et al (2001). N-[3, 4-dimethoxycinnamoyl]-anthranilic acid (tranilast) inhibits transforming growth factor- $\beta$ release and reduces migration and invasiveness of human malignant glioma cells. Int $J$ Cancer, 93, 53-61.

Rajabalian S (2008). Methanolic extract of Teucrium polium L potentiates the cytotoxic and apoptotic effects of anticancer drugs of vincristine, vinblastine and doxorubicin against a panel of cancerous cell lines. Exp Oncol, 2008.

Scappaticci FA (2002). Mechanisms and future directions for angiogenesis-based cancer therapies. $J$ Clin Oncol, 20, 3906-27.

Sheikhbahaei F, Khazaei M, Nematollahi-Mahani SN (2018). Teucrium polium extract enhances the anti-angiogenesis effect of tranilast on human umbilical vein endothelial cells. Adv Pharm Bull, 8, 131.

Stankovic MS, Mitrovic TL, Matic IZ, et al (2015). New values of Teucrium species: In vitro study of cytotoxic activities of secondary metabolites. Not Bot Horti Agrobot Cluj Napoca, 43, 41-6.

Strober W (2001). Trypan blue test of cell viability. Curr Protoc Immunol, 21.

Subramaniam V, Chakrabarti R, Prud'homme GJ, et al (2010). Tranilast inhibits cell proliferation and migration and promotes apoptosis in murine breast cancer. Anti Cancer Drugs, 21, 351-61.

Walker RA, Dearing SJ (1992). Transforming growth factor beta1 in ductal carcinoma in situ and invasive carcinomas of the breast. Eur J Cancer, 28, 641-4.

Yamamoto M, Yamauchi T, Okano K, et al (2009). Tranilast, an anti-allergic drug, down-regulates the growth of cultured neurofibroma cells derived from neurofibromatosis type 1 . Tohoku J Exp Med, 217, 193-201.

\section{(ब) $\odot \otimes$}

This work is licensed under a Creative Commons AttributionNon Commercial 4.0 International License. 